\title{
Infectious origin of the antiphospholipid syndrome*
}

\section{Y Shoenfeld, M Blank, R Cervera, J Font, E Raschi, P-L Meroni}

From a systemic disease towards the infectious aetiology

T he general consensus is that autoimmune diseases have a multifactorial aetiology, depending on both genetic and environmental factors. Microbial agents or viruses can induce autoimmune diseases by a variety of mechanisms. ${ }^{1}$ For example, proteins of certain infectious agents can act as polyclonal activators on unique lymphocyte subsets. Viruses can preferentially infect/destroy a particular $\mathrm{T}$ cell subset, leading to an imbalance in the immune response. Several microbial agents have been found to encode superantigens that can selectively activate subset(s) of $\mathrm{T}$ cells. Microbes can also direct the release of cytokines and chemokines, which can act as growth, differentiation, or chemotactic factors for different cell populations and regulate expression of major histocompatibility complex class I and class II as well as costimulatory molecules. $^{2}$

The healthy immune system is tolerant of the molecules of which the body is composed. However, one can find that among the major antigens recognised during a wide variety of bacterial, viral, and parasitic diseases, many belong to conserved protein families, sharing extensive sequence identity or conformational fits, with the host's molecules-namely, molecular mimicry. Antigenic similarity of the linear amino acid sequences of either molecule or their conformational structure between antigens of infectious agents and host tissues might trigger an immune response against the shared determinant. As a result, the tolerance to autoantigens breaks down, and the pathogen-specific immune response that is generated, cross reacts with host structures to cause tissue damage and disease. A role for molecular mimicry in the pathogenesis of autoimmune diseases has recently been shown in several animal models such as allergic encephalomyelitis, experimental myocarditis, and experimental autoimmune uveitis and keratitis. ${ }^{2}$

*The authors received the EULAR Prize, 2005 for this topic in a report entitled "The aetiology of the antiphospholipid syndrome (APS)".
The classical antiphospholipid syndrome (APS) is characterised by the presence of antiphospholipid antibodies (aPL) which bind target phospholipid molecules, mainly through $\beta_{2}$-glycoprotein I ( $\left.\beta_{2} \mathrm{GPI}\right)$, and are associated with recurrent fetal loss and thromboembolic phenomena..$^{3-5}$ Clinical and immunological evaluation of the patterns of disease expression in a cohort of 1000 patients and other clinical reports, led to the idea of "systemic APS". ${ }^{6}$ The APS afflicts up to two million patients, including many lupus patients, in the United States and Europe. Unlike the typical stroke patient, these patients often experience their first stroke, heart attack, or miscarriage in their 20s and 30 s and have twice the probability of a recurrence.

\section{"Many infections are associated} with increases in aPL"

The aetiology of the disease was deciphered only recently in an examination of the infectious origin of the APS.

\section{INFECTION AND} ANTIPHOSPHOLIPID ANTIBODIES

Many infections may be accompanied increases may be accompanied by clinical manifestations of the APS. ${ }^{7-9}$ Skin infections (18\%), human immunodeficiency virus (HIV) infection (17\%), pneumonia (14\%), hepatitis C virus (HCV) $(13 \%)$, and urinary tract infections constituted the most common infections found as "triggering" factors in the most recent review." In nine cases, more than one agent/organ was identified as the source of infection. Other infections less commonly associated with APS included mycoplasma (three cases), pulmonary tuberculosis (two cases), malaria (two cases), $P$ carinii, and leptospirosis (one case each).

Although IgM isotypes of the anticardiolipin antibodies seem mainly to be produced, increases in IgG have also been detected in some serum samples. Moreover, despite initial reports that aPL associated with infection were by increases in aPL and, in some, these $\beta_{2}$ GPI independent and non-pathogenic antibodies, several later studies clearly documented their reactivity with $\beta_{2}$ GPI. $^{10}{ }^{11}$

\section{Antibiotics in APS}

In contrast with rheumatic fever or other infectious autoimmunity related conditions, in APS it seems that the disease is derived through two hit mechanisms (see later text)-that is, the infections might have occurred long before the autoimmune manifestation emerges. Thus, the infection is not always apparent in the case of APS. Yet, two reports point to the effectiveness of antibiotics in APS and especially in the catastrophic subtype. In the first of these reports, of a patient with APS associated with $H$ pylori, all disease manifestations disappeared upon eradication of the bacteria. ${ }^{12}$ In the other-an experimental model of APS - the manifestations were abrogated by parallel treatment with ciprofloxacin. ${ }^{13}$

\section{THE CATASTROPHIC APS AND INFECTIONS}

An unusual and potentially fatal subset of the APS was first defined in 1992: the so called catastrophic APS. ${ }^{14}$ Since then, we have analysed the pathogenesis of catastrophic APS in more than 300 patients. ${ }^{15-19}$ We observed that "triggering" factors become increasingly apparent and were present in $51 \%$ of cases in the latest analysis. ${ }^{17}$ These factors included trauma (including surgical, both major and minor), anticoagulation withdrawal, a variety of carcinomas and, most importantly and commonly, infections, which were identified in $24 \%$ of these patients. Furthermore, our group described a refractory leg infection as an inducer of the catastrophic APS,${ }^{20}$ because the episode resolved after amputation of a gangrenous limb in two patients.

\section{POSSIBLE ORIGIN OF ANTI- $\beta_{2}$ GPI ANTIBODIES}

We suggest that molecular mimicry mechanism between the pathogen and the $\beta_{2}$ GPI molecule may be the cause of APS, based on: (a) a correlation between APS clinical manifestations and infectious agents in humans; $(b)$ the strong homology between $\beta_{2}$ GPI related peptides (target epitopes for anti- $\beta_{2} \mathrm{GPI}$ antibodies) and different common pathogens, in the protein databases. ${ }^{21-23}$

We have identified, from a hexapeptide phage display library, $\beta_{2}$ GPI related synthetic peptides which are recognised by human anti- $\beta_{2}$ GPI monoclonal antibodies generated by us from patients with APS ${ }^{24}$ These $\beta_{2} \mathrm{GPI} /$ peptides were found to be located on domain I-II (mimotope), domain III, and domain 

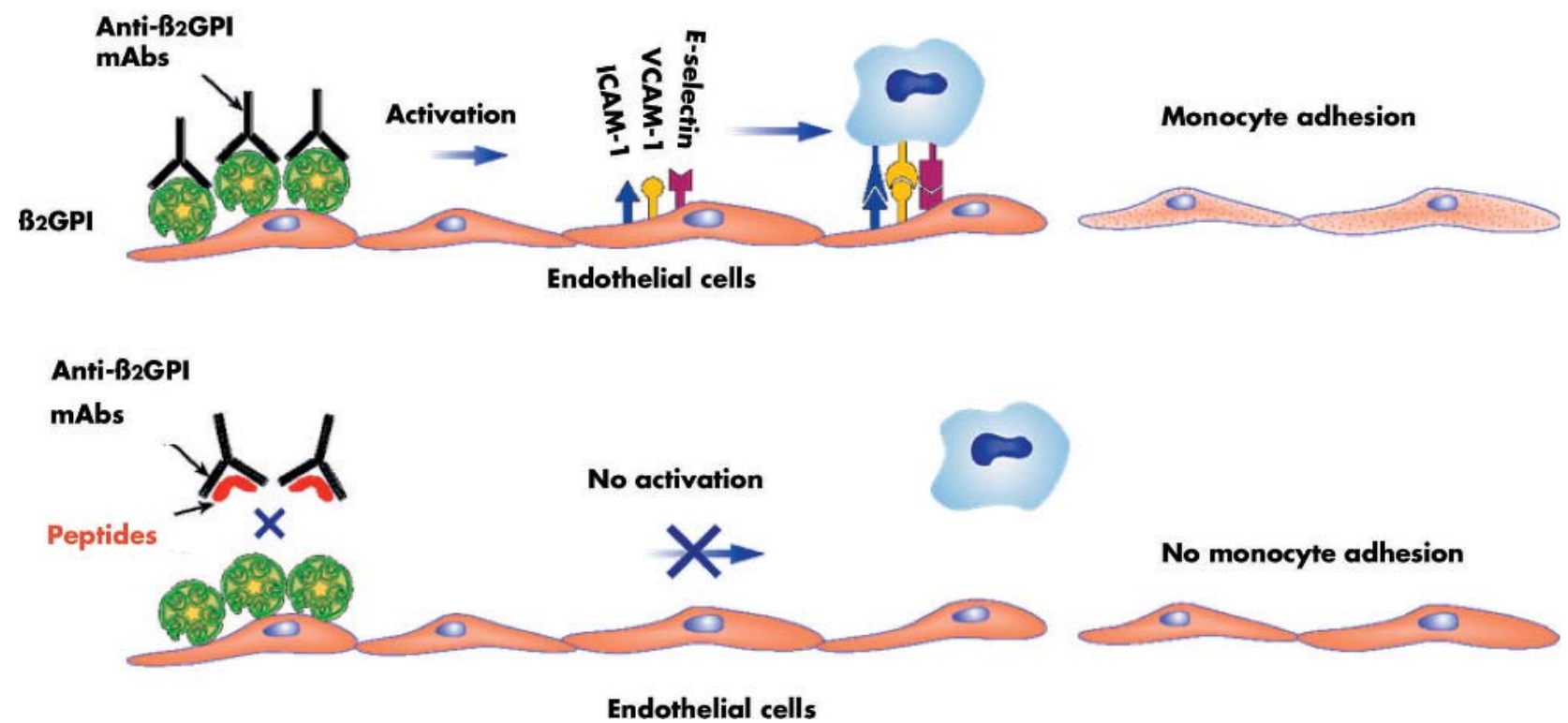

Figure 1 Endothelial cells subjected to anti- $\beta_{2}$ GPI are activated and express adhesion molecules such as ICAM-I and E-selectin. Previous incubation with synthetic peptides of $\beta_{2} \mathrm{GPI}$ prevent this activation.

IV (both linear sequences). All three synthetic peptides inhibited activation of endothelial cells in vitro and induced experimental APS in naive mice by neutralising the pathogenic anti- $\beta_{2}$ GPI antibodies (fig 1). We have demonstrated for the first time that patients with APS harbour a diverse panel of anti- $\beta_{2}$ GPI/peptide antibodies. ${ }^{24}$ Furthermore, we have analysed the prevalence of circulating anti-peptide A-C antibodies in sera of 295 patients with APS and found a range of 18 $47.5 \%{ }^{5}$

Employing the protein database, we found homologies between our peptides and other peptides with common bacteria viruses, yeast, and tetanus toxin. To prove the involvement of a molecular mimicry mechanism between the pathogen and the $\beta_{2}$ GPI molecule as a cause of experimental APS, we immunised naive mice with microbial pathogens, which share structural homology with $\beta_{2}$ GPI. After immunisation, various levels of mouse antibodies reacting with $\beta_{2}$ GPI were observed, the highest being detected in those mice immunised with Haemophilus influenzae, Neisseria gonorrhoeae or tetanus toxoid, and were specific for the molecular weight defined in the protein database, as shown by western blot. Mouse IgG specific to the TLRVYK peptide were affinity purified from the immunised mice on a TLRVYK column and passively infused intravenously into naive mice at day 0 of pregnancy (fig 2). APS clinical variables were evaluated in the infused mice on day 15 of pregnancy. Mice infused with these antibodies had significant thrombocytopenia, prolonged activated partial thromboplastin time (aPTT), and increased fetal loss, similar to the results for a control group of mice immunised with a pathogenic anti$\beta_{2}$ GPI monoclonal antibody. ${ }^{23}$ Hence, our study established for the first time a mechanism of molecular mimicry in experimental APS, demonstrating that $\beta_{2}$ GPI structurally homologous bacteria can induce the generation of anti- $\beta_{2}$ GPI pathogenic antibodies together with APS manifestations. ${ }^{25}$

\section{"Molecular mimicry between patho- gen and $\beta_{2}$-glycoprotein I may cause the APS"}

In parallel, Gharavi et al induced circulating antibodies cross reacting with $\beta_{2}$ GPI in naive mice by immunisation with synthetic peptides conjugated to bovine serum albumin, ${ }^{27}$ which share some similarity with the $72 \mathrm{kDa}$ human adenovirus type 2 DNA binding protein, human cytomegalovirus, and Bacillus subtilis. Gharavi et al induced aPL in mice by immunisation with GDKV, a 15-amino acid synthetic peptide that spans $\mathrm{Gly}^{274}$-Cys ${ }^{288}$ of $\beta_{2}$ GPI, which represents a major phospholipid binding region of this protein. ${ }^{28}$ These aPL were subsequently shown to be pathogenic, as demonstrated by their ability to enhance thrombus formation in a mouse model.

These findings led them to propose that viral peptides resembling GDKV might induce aPL, and that these antibodies might themselves be pathogenic. Therefore, they induced aPL in mice by immunisation with synthetic peptides of viral and bacterial origin that had sequence and functional similarity to the phospholipid binding site of $\beta_{2}$ GPI: TADL (spans $\mathrm{Thr}^{77}$-Glu ${ }^{96}$ of the $72 \mathrm{kDa}$ human adenovirus type 2 DNA binding protein), TIFI (spans $\mathrm{Thr}^{101}-\mathrm{Thr}^{120}$ of ULB0-HCMVA from human cytomegalovirus (CMV)), VITT (spans Val ${ }^{51}-$ Ile $^{70}$ of US27-HCMVA), and SGDF (spans $\mathrm{Ser}^{237}$-Ser $^{256}$ of TLPA-BACSU from Bacillus subtilis) ${ }^{29}$

In the next step, Gharavi et al determined whether these antibodies had functional and pathogenic properties similar to those found in aPL in patients with APS. ${ }^{30}$ They generated 10 murine monoclonal aPL from spleen cells of PL/ J mice immunised with TIFI. The antibodies generated had aPL activity that was inhibited by cardiolipin liposomes, and this inhibition was enhanced in the presence of $\beta_{2}$ GPI. Injection with two of the monoclonal aPL in mice significantly increased the number of leucocytes adhering to endothelial cells and 
- Tetanus toxoid

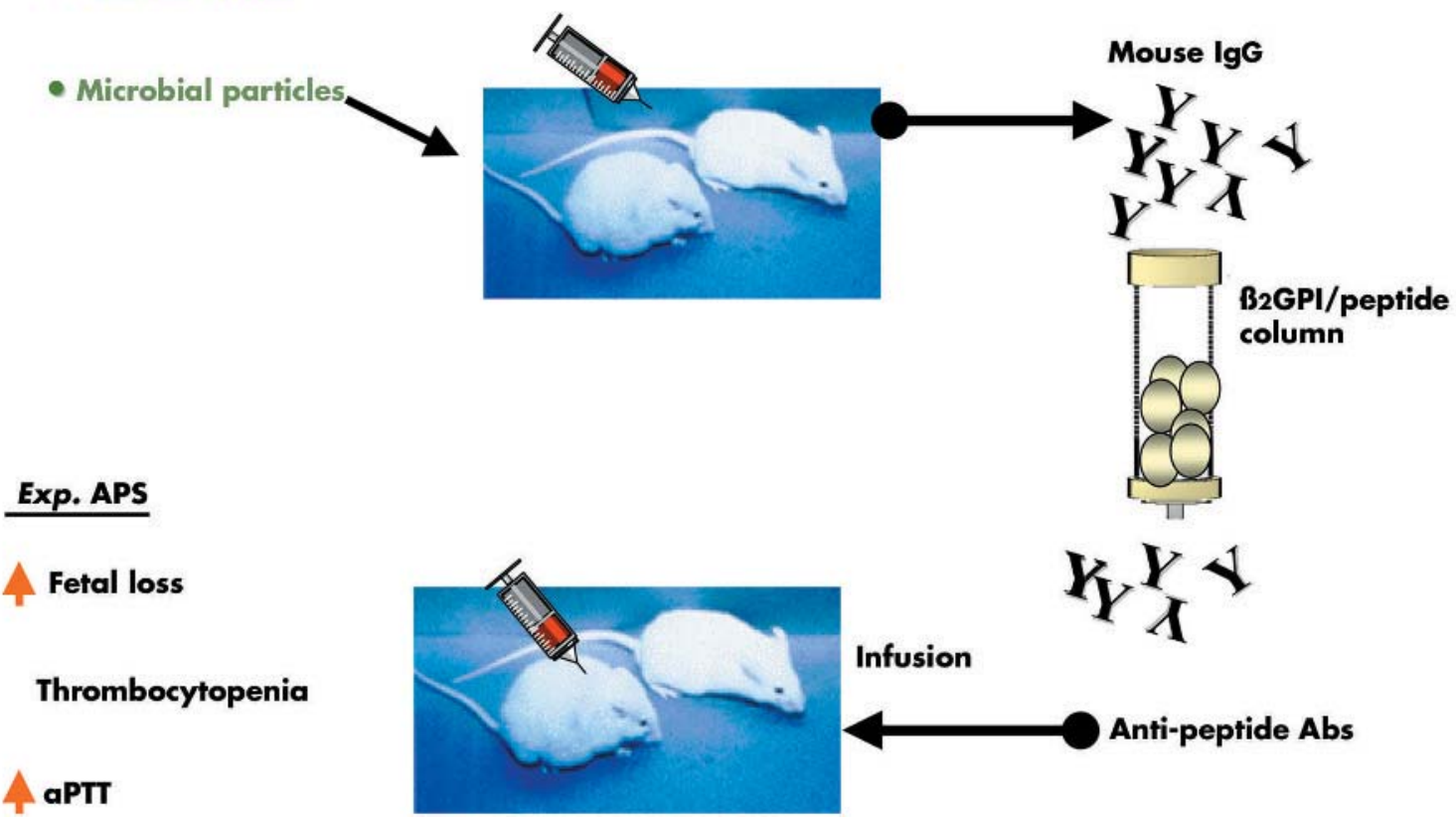

Figure 2 Active immunisation of mice with bacterial and viral particles induces anti- $\beta_{2} \mathrm{GPI}$ antibodies. The anti- $\beta_{2} \mathrm{GPI}$ antibodies when passively infused into another set of naive mice induce experimental APS.

enhanced thrombus formation in vivo. These results indicate that aPL induced by immunisation with a phospholipidbinding CMV peptide are pathogenic in vivo. The results also suggest a molecular mimicry mechanism by which pathogenic aPL may be generated in patients with APS.

"Pathogenic aPL may be generated in APS by a molecular mimicry mechanism"

Moreover, we assessed the ability of a $\beta_{2}$ GPI related synthetic peptide (NTLKTPRVGGC), ${ }^{31}$ which is similar to common bacterial antigens, to reverse aPL mediated thrombosis in mice in vivo. CDl mice were injected with affinity purified aPL or with control IgG intraperitoneally. Thrombosis was induced by a surgical procedure: the femoral vein of the anaesthetised mice was dissected to examine the dynamics of an induced thrombus in treated and control mice. The data indicated that a synthetic peptide that shares similarity with common bacterial antigens and with regions of $\beta_{2}$ GPI can inhibit thrombogenic properties of aPL in mice. We suggest that this $\beta_{2}$ GPI related synthetic peptide may have important implications in designing new modalities of prevention and/or treatment of thrombosis in APS. ${ }^{31}$

Recently, our group pointed to the possibility that Libman-Sacks non-bacterial endocarditis occurring in patients with APS may have an infectious origin. ${ }^{32}$ This proposal was based on a previous study in which $a P L / \beta_{2}$ GPI antibodies were located on the deformed human valves derived from patients with APS. ${ }^{33}$ The fine antigenic specificity of the deposited aPL was determined by (a) identifying their ability to bind biotinylated TLRVYK peptide and $(b)$ by showing that the same peptide could inhibit the binding of S2.9 (a monoclonal antibody specific for an aPL idiotype) to the deposited human $\mathrm{aPL} / \beta_{2} \mathrm{GPI}$ antibodies on the valvular endothelium. Thus, the aPL/ $\beta_{2}$ GPI antibodies located on the deformed valve from patients with APS might display a cross reactivity with peptides sharing homology with microbial molecules. ${ }^{32}$

We believe that pathogen particles are digested and presented on macrophages, dendritic cells, or on B cells. These pathogen particles are presented to $\mathrm{T}$ cells, which in concert with appropriate HLA presentation and Th1/Th2 activated cytokine cascade expression will lead to the generation of plasma cells secreting antibodies directed to the pathogen particles, which share structural homology (molecular mimicry) with the $\beta_{2} \mathrm{GPI}$ molecule. Whether a person will develop APS will depend mainly on his genetic predisposition, which may or may not favour the production of the cross reacting autoantibodies.

$\beta_{2}$ GPI polymorphism (in particular the $\mathrm{Val}^{247}$ allele) has recently been associated with both a high frequency of anti- $\beta_{2}$ GPI antibodies and stronger antibody reactivity than the $\mathrm{Leu}^{247}$ $\beta_{2}$ GPI allele. ${ }^{34}{ }^{35}$ Such a finding may represent an additional variable that might favour the occurrence of molecular mimicry between infectious molecules and molecular variants of the aPL antigenic target.

\section{ANTI- $\beta_{2}$ GPI ANTIBODIES AND RECEPTORS OF THE INNATE IMMUNITY IN APS}

Considerable reported evidence suggests that $\beta_{2}$ GPI is the main antigenic target for aPL. Besides its presence in plasma, it is also expressed on the surface membranes of different cell types involved in the pathogenesis of the syndrome-namely, endothelial cells, monocytes, and trophoblasts. ${ }^{36}$

It has been suggested that anti- $\beta_{2}$ GPI antibodies might recognise and cluster the molecule bound to its own endothelial 
cell membrane receptor(s), eventually inducing the signal events leading to the induction of a proinflammatory and procoagulant phenotype. Accordingly, it has been suggested that anti- $\beta_{2}$ GPI antibody mediated endothelial cell activation is one of the pathogenic mechanisms of the APS thrombophilic diathesis. ${ }^{37}$

The definition of endothelial cell membrane receptor(s) for $\beta_{2}$ GPI as well as the signalling pathways involved have been examined only recently. Evidence suggests that the putative $\beta_{2}$ GPI phospholipid binding site might be involved in the binding to anionic endothelial cell structures such as heparan sulphate as well as to annexin $\mathrm{A}_{2}$, the receptor for plasminogen/tissue plasminogen activator. ${ }^{38}$

Our group has recently shown that both human monoclonal and polyclonal anti- $\beta_{2}$ GPI antibodies induce an endothelial signalling cascade comparable to that activated by lipopolysaccharide (LPS) through the involvement of toll-like receptor (TLR)-4. ${ }^{39}$ Moreover, it has been suggested also that annexin $\mathrm{A}_{2}$ does require TLR- 4 as a co-receptor to signal, because annexin $A_{2}$ binds $\beta_{2}$ GPI with high affinity but it does not display any transmembrane protein. ${ }^{40}$ Finally, our group has recently shown that aPL mediated thrombosis is significantly reduced in mice displaying the $t l r-4$ gene mutation that leads to an impaired LPS response. Accordingly, we also found that $\mathrm{Asp}^{299}$-Gly polymorphism of gene tlr-4-associated with a reduced LPS response-is significantly less common in patients with APS with thrombosis than in healthy controls (Pierangeli et al, submitted). As a whole, these findings speak in favour of the involvement of TLR-4 dependent signalling in the pathogenesis of APS.

TLRs are a key component of the innate immune response, which can recognise specific microbial products, including LPS. ${ }^{40}$ Being transmembrane proteins, all the members of the TLR family behave as efficient receptors able to drive a prompt inflammatory response after their interaction with specific ligands. TLRs are widely expressed in both lymphoid and nonlymphoid tissues, including, in particular, endothelial cells, which display a significant amount of TLR-4.

As previously mentioned, $\beta_{2}$ GPI displays homology with common bacteria and viruses that are the natural ligands for the TLRs. Thus, we speculate that $\beta_{2}$ GPI-alone or complexed with its own endothelial cell membrane receptors-might interact with TLRs, and that anti- $\beta_{2}$ GPI antibodies recognising the molecule might cross link it with the TLRs, eventually triggering the signalling cascade.
A two hit hypothesis has been suggested to explain the common clinical observation that aPL might be persistently present but that thrombotic events occur only occasionally: aPL (first hit) increases the thrombophilic risk and clotting takes place in the presence of another thrombophilic condition. ${ }^{41}$ As stated above, infectious processes frequently precede the full blown picture of the syndrome. We hypothesise that involvement of TLRs by microbial structures together with that mediated by anti- $\beta_{2}$ GPI antibodies might synergistically contribute to the second hit that triggers the clotting event. Such a possibility is in line with a recent in vivo experimental model reported by our group. Human anti- $\beta_{2}$ GPI IgG infused into naive rats do not significantly affect the mesenteric microcirculation; however, the same IgG fractions trigger clotting if a priming proinflammatory factor-such as LPS-is present. ${ }^{42}$ As a whole, these findings support the role of infectious agents as a second hit and the involvement of receptors of the innate immunity at the same time.

In conclusion, the molecular mimicry between $\beta_{2}$ GPI and microbial products is one aspect of the infectious origin of APS while another aspect is represented by the engagement of the innate immunity receptors usually involved in sensing microbial agents.

Ann Rheum Dis 2006;65:2-6.

doi: 10.1136/ard.2005.045443

\section{Authors' affiliations}

Y Shoenfeld, M Blank, Department of Medicine " $B$ " and Centre for Autoimmune Diseases, Sheba Medical Centre, Tel-

Hashomer, and Sackler Faculty of Medicine, Tel-Aviv University, Israel

R Cervera, J Font, Department of Autoimmune Diseases, Institut Clinic de Medicina i Dermatologia, Hospital Clinic, Barcelona,

Catalonia, Spain

E Raschi, P-L Meroni, Allergy, Clinical Immunology and Rheumatology Unit, Department of Internal Medicine, University of Milan, IRCCS Istituto Auxologico Italiano, Milan, Italy

Correspondence to: Professor Y Shoenfeld, Head, Department of Medicine " $B$ " and Centre for Autoimmune Diseases, Sheba Medical Centre, Tel-Hashomer 52621, Israel; shoenfel@ post.tau.ac.il

Y Shoenfeld: Incumbent of the Laura SchwarzKipp Chair for Autoimmunity, Tel-Aviv University, Israel

\section{REFERENCES}

1 Shoenfeld Y, Cervera R. Innovations in autoimmunity in the last decade. In: Shoenfeld $Y$, eds. The decade of autoimmunity. Amsterdam: Elsevier, 1999:7-18.

2 Shoenfeld Y, Rose NR, eds. Infection and autoimmunity. Amsterdam: Elsevier, 2004.
3 Asherson RA, Cervera R, Piette JC, Shoenfeld Y Milestones in the antiphospholipid syndrome. In Asherson RA, Cervera R, Piette JC, Shoenfeld Y, Piette J-C, eds. The antiphospholipid syndrome II Autoimmune thrombosis. Amsterdam: Elsevier, 2002

4 Cervera R, Piette JC, Font J, Khamashta MA, Shoenfeld Y, Camps MT, et al. Antiphospholipid syndrome: clinical and immunologic manifestations and patterns of disease expression in a cohort of 1,000 patients. Arthritis Rheum 2002;46:1019-27.

5 Shoenfeld Y, Krause I, Kvapil F, Sulkes J, Lev S, von Landenberg $P$, et al. Prevalence and clinical correlations of antibodies against six beta2glycoprotein-I-related peptides in the antiphospholipid syndrome. J Clin Immunol 2003:23:377-83.

6 Shoenfeld Y. Systemic antiphospholipid syndrome. Lupus 2003;12:497-8.

7 Zandman-Goddard G, Blank M, Shoenfeld Y Antiphospholipid antibodies and infections drugs. In: Asherson RA Cervera R, Shoenfeld Y, Piette J-C, eds. The antiphospholipid syndrome II Autoimmune thrombosis. Amsterdam: Elsevier, 2002:343-58.

8 Asherson RA, Cervera R. Antiphospholipid antibodies and infections. Ann Rheum Dis 2003;62:388-93.

9 Cervera R, Asherson RA, Acevedo ML, GomezPuerta JA, Espinosa G, De La Red G, et al. Antiphospholipid syndrome associated with infections: clinical and microbiological characteristics of 100 patients. Ann Rheum Dis 2004;63:1312-17.

10 Loizou S, Cazabon JK, Walport MJ, Tait D, So AK, Similarities of specificity and cofactor dependence in serum antiphospholipid antibodies from patients with human parvovirus B19 infection and from those with systemic lupus erythematosus. Arthritis Rheum 1997;40:103-8.

11 Gharavi AE, Pierangeli S. Infections and antiphospholipid syndrome. In: Khamashta MA, eds. Hughes syndrome - antiphospholipid syndrome. London: Springer, 2000:135-43.

12 Gasbarrini A, Gasbarrini G. Disappearance of APS after Helicobacter pylori eradication. Am J Med 2001;111:163.

13 Blank M, George J, Fishman P, Levy Y, Toder V, Savion $S$, et al. Ciprofloxacin immunomodulation of experimental antiphospholipid syndrome associated with elevation of interleukin-3 and granulocyte-macrophage colony-stimulating factor expression. Arthritis Rheum 1998:41:224-32.

14 Asherson RA. The catastrophic antiphospholipid syndrome. J Rheumatol 1992;19:508-12.

15 Asherson RA, Cervera R, Piette JC, Font J, Lie JT, Burcoglu A, et al. Catastrophic antiphospholipid syndrome. Clinical and laboratory features of 50 patients. Medicine (Baltimore) 1998;77:195-207.

16 Asherson RA, Cervera R, Piette JC, Shoenfeld $Y$ Espinosa G, Petri MA, et al. Catastrophic antiphospholipid syndrome: clues to the pathogenesis from a series of 80 patients. Medicine (Baltimore) 2001 :80:355-77.

17 Cervera R, Gómez-Puerta JA, Espinosa G, Font J, De la Red G; Gil V, et al. "CAPS Registry". A review of 200 cases from the international registry of patients with the catastrophic antiphospholipid syndrome (CAPS) [abstract] Ann Rheum Dis 2003;62(suppl 1):88.

18 Rojas-Rodriguez J, Garcia -Carrasco M, RamosCasals M, Enriquez-Coronel G, Colchero C, Cervera R, et al. Catastrophic antiphospholipid syndrome: clinical description and triggering factors in 8 patients. $J$ Rheumatol 2000;27:238-40.

19 Asherson R, Cervera R, de Groot PG, Erkan D, Boffa MC, Piette JC, et al. Catastrophic antiphospholipid syndrome: international consensus statement criteria and treatment guidelines. Lupus 2003;12:530-4.

20 Amital H, Levy Y, Davidson C, Lundberg I, Hariu A, Kosach Y, et al. Catastrophic antiphospholipid syndrome: remission following leg amputation in 2 cases. Semin Arthritis Rheum 2001;31:127-32.

21 Blank M, Shoenfeld Y. Beta-2-glycoprotein-I, infections, antiphospholipid syndrome and 
therapeutic considerations. Clin Immunol 2004; 112:190-9.

22 Blank M, Asherson RA, Cervera R, Shoenfeld Y Antiphospholipid syndrome infectious origin. J Clin Immunol 2004;24:12-23.

23 Asherson RA, Shoenfeld Y. The role of infection in the pathogenesis of catastrophic antiphospholipid syndrome-molecular mimicry? J Rheumatol 2000;27:12-14.

24 Blank M, Shoenfeld Y, Cabilli S, Heldman Y, Fridkin $M$, Katchalski-Katzir E. Prevention of experimental antiphospholipid syndrome and endothelial cell activation by synthetic peptides. Proc Natl Acd Sci USA 1999;96:5164-8.

25 Blank M, Krause I, Fridkin M, Keller N, Kopolovic J, Goldberg I,et al, Bacterial induction of autoantibodies to beta2-glycoprotein-I accounts for the infectious etiology of antiphospholipid syndrome. J Clin Invest 2002;109:797-804.

26 Shoenfeld Y. Etiology and pathogenetic mechanisms of the anti-phospholipid syndrome unraveled. Trends Immunol 2003;24:2-4.

27 Gharavi AE, Pierangeli SS, Espinola RG, Liu X, Colden-Stanfield M, Harris EN. Antiphospholipid antibodies induced in mice by immunization with a cytomegalovirus-derived peptide cause thrombosis and activation of endothelial cells in vivo. Arthritis Rheum 2002;46:545-52.

28 Gharavi AE, Pierangeli SS, Colden-Stanfield $M$, Liu XW, Espinola RG, Harris EN. GDKV-induced antiphospholipid antibodies enhance thrombosis and activate endothelial cells in vivo and in vitro $\mathrm{J}$ Immunol 1999; 163:2922-7.
29 Gharavi EE, Chaimovich H, Cucurull E, Celli CM, Tang $\mathrm{H}$, Wilson WA, et al. Induction of antiphospholipid antibodies by immunization with viral and bacterial peptides. Lupus 1999;8:449-55.

30 Gharavi AE, Pierangeli SS, Espinola RG, Liu X, Colden-Stanfield M, Harris EN. Antiphospholipid antibodies induced in mice by immunization with a cytomegalovirus-derived peptide cause thrombosis and activation of endothelial cells in vivo. Arthritis Rheum 2002;46:545-52

31 Pierangeli SS, Blank $M$, Liu X, Espinola R, Fridkin $M$, Ostertag $M V$, et al. A peptide that shares similarity with bacterial antigens reverses thrombogenic properties of antiphospholipid antibodies in vivo. J Autoimmun 2004:22:217-25.

32 Blank M, Shani A, Goldberg I, Kopolovic J, Amigo MC, Magrini L, et al. Libman-Sacks endocarditis associated with antiphospholipid syndrome and infection. Thromb Res 2004; 114:589-92.

33 Ziporen L, Goldberg I, Arad M, Hojnik M, OrdiRos J, Afek A, et al. Libman-Sacks endocarditis in the antiphospholipid syndrome: immunopathologic findings in deformed heart valves. Lupus 1996;5:196-205.

34 Prieto GA, Cabral AR, Zapata-Zuniga M, Simon AJ, Villa AR, Alarcon-Segovia D, et al. Valine/valine genotype at position 247 of the beta 2 glycoprotein I gene in Mexican patients with primary antiphospholipid syndrome: association with anti-beta2 glycoprotein I antibodies. Arthritis Rheum 2003;48:471-4.
35 Yasuda S, Atsumi T, Matsuura E, Haihara K, Yamamoto D, Ichikawa K, et al. Significance of valine/leucine 247 polymoprhism of beta 2 glycoprotein I in antiphospholipid syndrome: increased reactivity of anti-beta2 glycoprotein I autoantibodies to the valine 247 beta 2 glycoprotein I variant. Arthritis Rheum 2005; 52:212-18.

36 Meroni PL, Riboldi P. Pathogenic mechanisms mediating antiphospholipid syndrome. Curr Opin Rheumatol 2001;13:377-82.

37 Meroni PO, Raschi E, Testoni C, Borghi MO. Endothelial cell activation by antiphospholipid antibodies. Clin Immunol 2004; 112:169-74.

38 Zhang J, McCrae KR. Annexin A2 mediates endothelial cell activation by antiphospholipid/ anti-beta2-glycoprotein I antibodies. Blood 2005; 105: 1964-9.

39 Raschi E, Testoni C, Bosisio D, Borghi MO, Koike T, Mantovani A,et al, Role of the MyD88 transduction signaling pathway in endothelial activation by antiphospholipid antibodies. Blood 2003;101:3495-500.

40 Medzhitov R. Toll-like receptors and innate immunity. Nat Rev Immunol 2001;1:135-45.

41 Meroni PL, Riboldi P. Pathogenic mechanisms mediating antiphospholipid syndrome. Curr Opin Rheumatol 2001;13:377-82.

42 Fischetti F, Durigutto $P$, Pellis V, Debeus A, Macor $P$, Bulla R, et al. Thrombus formation induced by antibodies to beta2-glycoprotein I is complement-dependent and requires a priming factor. Blood 2005; 106 2340-6. 